\title{
Urbanismo proempresarial y viviendas desocupadas en el área metropolitana de Buenos Aires: el caso de la ciudad de Lomas de Zamora
}

\author{
Pro-business urbanism and unoccupied housing in the Buenos Aires metropolitan \\ area. The case of the city of Lomas de Zamora.
}

Bárbara Teresa Romano

Universidad Nacional de Tres de Febrero (UNTREF) Consejo Nacional de Investigaciones Científicas y Técnicas (CONICET)

Argentina

bromano@unterf.edu.ar

\section{RESUMEN}

El proceso de recuperación económica que se vivenció luego de la crisis económica, social y política del año 2001 en la Argentina, representó una oportunidad, fundamentalmente, para el sector de la construcción y de los negocios inmobiliarios. Las inversiones de los promotores inmobiliarios, amparados por los mismos gobiernos locales, se concentraron no solamente en los tradicionales barrios de la Ciudad Autónoma de Buenos Aires, sino también en zonas poco exploradas por el urbanismo proempresarial: las localidades cabeceras de los partidos del Área Metropolitana de Buenos Aires (AMBA). Una de ellas es Lomas de Zamora, que se ubica en el corredor sur del aglomerado, y ha experimentado un reciente proceso de verticalización que ha contribuido a la expansión de las viviendas desocupadas. En esta presentación, nos proponemos analizar la cantidad y distribución de viviendas desocupadas, a través de la información presente en los tres últimos censos nacionales de población, hogares y viviendas (INDEC, 1991 - 2001-2010), en contraposición al crecimiento de la población residencial que parece estancado; con un enfoque que pretende interpretar las características que están por detrás del fenómeno (¿o estrategia inmobiliaria?) de las viviendas desocupadas.

PALABRAS CLAVE: vivienda desocupada, alquiler, financiarización de la vivienda, Lomas de Zamora. 


\begin{abstract}
The process of economic recovery that was experienced after the economic, social and political crisis of 2001 in Argentina, represented an opportunity, fundamentally, for the construction and real estate business sector. The investments of the real estate developers, protected by the same local governments, concentrated not only in the traditional neighborhoods of the Ciudad Autónoma of Buenos Aires, but also in areas little explored by the pro-business urbanism: the head towns of the partidos of Buenos Aires Metropolitan Area (AMBA). One of them is Lomas de Zamora, which is located in the southern corridor of the agglomerate, and has undergone a recent verticalization process that has contributed to the expansion of houses discovered. In this presentation, we propose to analyze the quantity and distribution of houses discovered, through the information present in the last three national censuses (INDEC, 1991 - 2001-2010), as opposed to population growth residential that seems stagnant; with an approach that tries to interpret the characteristics that are behind the phenomenon (or real estate strategy?) of vacant houses.
\end{abstract}

KEYWORDS: unoccupied housing, rental, housing financing, Lomas de Zamora.

\title{
INTRODUCCIÓN
}

En el periodo poscrisis 2001 la Argentina experimentó una notable recuperación tras la salida del régimen de convertibilidad, la estabilización y crecimiento positivo de la balanza comercial y la restitución de la figura de las retenciones a las exportaciones. Autores como Del Río. J., (2014); Guevara, T., (2014); Dalle, P., (2010) coinciden en señalar que la pérdida de la participación del endeudamiento externo en la economía nacional, posibilitó la consolidación de un escenario para establecer un dólar alto que permitió crear las condiciones para una recuperación de los sectores productivos orientados al mercado interno y, además, mejorar la competitividad para los exportadores. Se inició una etapa de fuerte crecimiento de la actividad económica, que se tradujo fundamentalmente en el Producto Bruto Interno y en el empleo; el cual ocasionó un aumento generalizado del consumo interno y disminución de la pobreza. Para Dalle, P., (2010) se produjo un cierto "derrame" de prosperidad, sobre todo hacia los sectores bajos y medios bajos, donde la crisis había tenido un mayor impacto. 
Con los primeros signos de la recuperación económica, el sector de la construcción y el negocio inmobiliario funcionaron como uno de los motores de la economía, en zonas donde la rentabilidad estaba asegurada. Para Baer, L., (2012) se conjugaron varios factores: suelo barato, bajos costos de construcción (mano de obra y materiales de construcción) y bajas tasas de interés (las oportunidades de inversión condujeron a la capitalización de los recursos financieros en el desarrollo inmobiliario y en la compra de viviendas). El carácter empresarialista en la planificación de las ciudades se manifestó -o mejor dicho se reforzó- a través de la apertura externa de muchas economías locales, que generaron las condiciones para estimular la llegada de capitales, principalmente del sector inmobiliario (Harvey, D., 2001). Esas condiciones, se tradujeron en el establecimiento de un escenario apropiado para que los actores privados puedan dirigir sus inversiones dentro de la ciudad entre las zonas que representan mayor rentabilidad. Se produjeron nuevos desarrollos inmobiliarios en forma de "countries en altura", "lofts" y reciclajes urbanos ligados a procesos de gentrificación. También se invirtió en la expansión de un formato de consumo, que ya venía desarrollándose desde la década de 1990: los shoppings centers y las urbanizaciones cerradas.

Las oportunidades de inversión para los promotores inmobiliarios se concentraron no solamente en los tradicionales barrios de la Ciudad Autónoma de Buenos Aires, sino también en zonas poco exploradas por el urbanismo proempresarial: las localidades cabeceras de los partidos del Área Metropolitana de Buenos Aires ${ }^{1}$. En este punto, destaquemos que el Área Metropolitana de Buenos Aires está compuesto por la Ciudad Autónoma de Buenos Aires y 24 partidos que, al mismo tiempo, se dividen en los partidos de la "primera corona" (Avellaneda, Quilmes, Lanús, Lomas de Zamora, La Matanza, Tres de Febrero, Morón, Ituzaingó, Hurlingham, General San Martín, Vicente López y San Isidro) y los partidos de la "segunda corona" (Berazategui, Florencio Varela, Almirante Brown, Esteban

\footnotetext{
${ }^{1}$ La República Argentina está dividida en 23 provincias. La provincia de Buenos Aires está dividida administrativamente en 135 partidos o municipios, para el año 2009. Cada partido tiene una o varias localidades, y una de ellas es la principal y se denominada "cabecera". Allí es donde está la sede del gobierno municipal.
} 
Echeverría, Ezeiza, Merlo, Moreno, San Miguel, José C. Paz, Malvinas Argentinas, Tigre y San Fernando), Figura 1.

En este trabajo, el objetivo es analizar la disposición de viviendas desocupadas en la ciudad de Lomas de Zamora, considerando a la población involucrada, el rol del Estado y el del mercado. La problemática que busca analizar este artículo es el aumento sostenido de la cantidad de viviendas desocupadas en la ciudad de Lomas de Zamora. De acuerdo al INDEC (Instituto Nacional de Estadísticas y Censos) se entiende como vivienda desocupada a "aquella que no se utiliza como residencia habitual de un hogar y nadie pernoctó en ella en la víspera del censo. Se diferencia según el motivo por el que se encontraban desocupadas: de veraneo o de fin de semana, en alquiler o venta, en construcción, usada con fines no habitacionales, por otra razón" (INDEC resultados definitivos para Buenos Aires, 1991: 21).

La financiarización de la vivienda impulsó la participación de bancos, empresas constructoras, desarrolladores inmobiliarios, fondos de inversión e incentivaron transformaciones urbanas (Rolnik, R., 2017) que, en nuestro caso, promovieron la creación de una zona apodada por los promotores inmobiliarios como "Las Lomitas". La zona en cuestión está atravesando procesos de inquilinización, en forma contemporánea con la pérdida relativa de propietarios (Romano, B., 2018b).

El auge inmobiliario de la década del 2000 demuestra un aumento sostenido de la cantidad de viviendas nuevas en la ciudad de Lomas de Zamora, principalmente de departamentos, que llegan a triplicar a los existentes en la década de 1990. Al mismo tiempo, y de acuerdo al análisis de los datos proporcionados por el INDEC (censos de $1991,2001,2010$ ) la cantidad de habitantes en nuestra área de estudio se mantiene estable y, en algunas zonas, presenta leves incrementos en su variación intercensal.

Frente a este panorama, en esta presentación nos proponemos analizar la cantidad y distribución de viviendas desocupadas, a través de la información presente en los tres últimos censos nacionales, en contraposición al crecimiento de la población residencial que parece estancado; con un enfoque que pretende interpretar las estrategias que están por detrás del fenómeno de las viviendas desocupadas.

El aumento de la cantidad de viviendas vacías se relaciona fundamentalmente con el alquiler, puesto que esas viviendas vacías -que son "retenidas" y no se colocan en el 
mercado- están "empujando" el precio de los alquileres. Una de las consecuencias es que aumenta la cantidad de dinero que cada familia destina al gasto en alquiler, lo que repercute en los niveles de pobreza y, entonces, en la delimitación del valor de la canasta básica. ${ }^{2}$

\section{El fenómeno de las casas vacías: una problemática del urbanismo proempresarial}

Tras la crisis del 2001 y luego de la devaluación del peso argentino, la industria de la construcción intensificó su protagonismo en el conjunto de la economía (apoyado por el sector público, que impulsó medidas económicas neokeynesianas), por su capacidad de incrementar la inversión y el consumo (Del Río, J., 2014; Guevara, T., 2014). En este contexto, y tras el colapso del sistema bancario y la desconfianza generalizada de la población hacia esas instituciones, el ahorro a través del "ladrillo" resultó ser la mejor opción financiera.

Sin embargo, la multiplicación de la oferta residencial no se tradujo en mayores posibilidades de acceso a la vivienda, de hecho, se registra "mucha gente sin casa y muchas casas sin gente" de acuerdo al Diagnóstico socio-habitacional de la Ciudad Autónoma de Buenos Aires (Comisión de Vivienda del Consejo Económico y Social 2016:11).

Una de las tantas causas que combina expansión inmobiliaria e imposibilidad de acceso a la vivienda propia formal, es la dificultad de acceso al crédito hipotecario. La implementación del modelo económico neodesarrollista, impulsó la recomposición salarial del segmento poblacional de ingresos medios, pero aquello no alcanzó para revertir la tendencia del aumento de inquilinos. Esta imposibilidad estuvo determinada por las altas tasas bancarias y por el aumento del valor del suelo,

\footnotetext{
${ }^{2}$ Según las mediciones de pobreza que realiza el INDEC, a través de la EPH, en el mes de abril del año 2019, una familia tipo precisaba para cubrir la canasta básica \$29.304 para no ser pobre. Si esa familia es inquilina necesita sumar el valor del alquiler, que se estipula en $\$ 19.472$ para un departamento de 3 ambientes en la Ciudad Autónoma de Buenos Aires. Por lo tanto esa familia necesita $\$ 48.776$ mensuales, para no ser pobre. Es decir que, en la actualidad las familias que alquilan destinan prácticamente el valor de otra canasta básica, al mantenimiento mensual de la vivienda si además se suma, por ejemplo, el valor de las expensas.
} 
que se tradujo, al mismo tiempo, en el aumento del valor de los alquileres y en la dificultad de ahorro por parte de los inquilinos.

El boom inmobiliario que sucedió a la crisis del 2001, no fue financiado por créditos hipotecarios sino por los ingresos y ahorros de una parte de la población de nivel socioeconómico medio y alto; que colocó en los "ladrillos" sus ahorros frente a la desconfianza al sistema bancario (Del Río. J., 2014). La expansión de las viviendas no se reflejó en una disminución de los inquilinos ni en un aumento de los propietarios, sino en un aumento de la cantidad de viviendas vacías.

Según el censo del año 2010, la Ciudad Autónoma de Buenos Aires cuenta con 1.425.840 viviendas, sobre un total de población de 2.890.151 habitantes. La relación directa entre estos dos números, se traduce en que existen alrededor de una vivienda cada dos habitantes, sin embargo esta relación está muy alejada de la realidad porteña puesto que varios estudios indican que existen una gran cantidad de viviendas deshabitadas o subocupadas, otras en condiciones de hacinamiento y otras tantas cuyo grado de deterioro impide la práctica de las funciones básicas de habitar (Rodríguez, et al 2016) ${ }^{3}$. Por otra parte, los datos sobre la cantidad de viviendas vacías se extraen de los censos nacionales de hogares, población y vivienda que realiza el INDEC cada 10 años, por lo que el censo proporciona una imagen estática sobre el proceso de ocupación de las viviendas y no muestra los cambios no siempre previsibles y los usos temporales de los inmuebles en cuestión. En este punto, cabe destacar que en los primeros meses del año 2019 se presentaron los primeros resultados de un estudio realizado por el Instituto de la Vivienda de la Ciudad (IVC); en donde se midió la cantidad de viviendas vacías a través del consumo eléctrico ${ }^{4}$. El principal objetivo es obtener una medición que atienda a las situaciones coyunturales, con respecto a la ocupación de la vivienda. De allí se desprende que en la CABA existen 138.328 viviendas vacías, según las mediciones realizadas por el Ente Nacional Regulador de Electricidad (ENRE) a través del consumo de electricidad

\footnotetext{
${ }^{3}$ Las viviendas subocupadas son aquellas que, siendo de uso residencial, no posee habitantes de manera recurrente sino sólo de manera temporal. Se suelen usar para vacaciones, fin de semana u otro uso temporal.
}

${ }^{4}$ https://www.cels.org.ar/web/2019/08/viviendas-vacias-en-la-ciudad-y-emergencia-habitacional/ 
domiciliaria, durante el año 2017. Según el IVC, una segunda fase del estudio analizará la evolución del consumo eléctrico durante la última década.

Hasta el año 2010, según el censo, existían en la ciudad 340.975 inmuebles deshabitados en la Ciudad Autónoma de Buenos Aires es decir que el $23,9 \%$ de las viviendas estaban desocupadas. En la zona norte, principalmente en las Comunas 1 , 14 y 2 , se concentran el $38,5 \%$ del total de viviendas deshabitadas 5 . Por el contrario, en la zona sur es donde se encuentran los mayores coeficientes de ocupación ${ }^{6}$. Los barrios que poseen mayor cantidad de viviendas ociosas se encuentran en el norte de la ciudad: Recoleta $(34,50 \%)$ y Palermo $(29,47)$, seguidos por Belgrano, Colegiales y Núñez (24,58\%). Luego se destacan algunos barrios del sur como San Cristóbal y Balvanera, en donde hay un $25,20 \%$ de viviendas vacías; mientras que en el centro geográfico de la ciudad sobresale el barrio de Caballito con $21,85 \%$ de sus viviendas ociosas. Destacamos que la concentración de viviendas ociosas se produce en aquellos barrios que históricamente agruparon las mejores condiciones sociohabitacionales de la capital federal (Torres, H., 1978, 2001; Álvarez, G, e lulita, A., 2013).

Si realizamos un cambio de escala y comparamos los valores de la Ciudad Autónoma de Buenos Aires (CABA) con los partidos del Área Metropolitana de Buenos Aires (AMBA), encontramos que existe una gran distancia con respecto a los porcentajes de viviendas desocupadas. CABA posee casi un $24 \%$ de su parque de viviendas desocupadas mientras que los partidos del AMBA poseen, en promedio, un $11,47 \%$. Señalemos, además, que los mayores porcentajes de viviendas ociosas en los partidos del AMBA no superan el $18 \%$ mientras que los menores porcentajes apenas superan el $8 \%$.

En el análisis de los partidos que componen el Área Metropolitana de Buenos Aires, destacamos que los partidos de Vicente López (17,19\%), Tigre $(16,71 \%)$, Ezeiza $(15,32)$ y San Isidro $(14,64 \%)$ son los que poseen los mayores porcentajes de

\footnotetext{
${ }^{5}$ La Ciudad Autónoma de Buenos Aires está organizada en 15 comunas, que se rigen bajo la ley 1.777/2005. Cada comuna está compuesta por uno o varios barrios. La comuna 1 está compuesta por los barrios de Retiro, Puerto Madero, San Nicolás, San Telmo. Monserrat, Constitución. La comuna 2 es el barrio de Recoleta, mientras que la comuna 14 es el barrio de Palermo.
}

${ }^{6}$ http://www.defensoria.org.ar/wp-content/uploads/2015/09/SituacionHabitiacional-1.pdf 
viviendas desocupadas, según el último censo realizado en el año 2010. Mientras que Merlo (8,03\%), Malvinas Argentinas (8,12\%), Almirante Brown (8,60\%) y Florencio Varela $(8,64 \%)$ son los partidos que tienen menores porcentajes de viviendas ociosas. En este conjunto, el partido de Lomas de Zamora -donde se inserta nuestro caso de estudio- se ubica en una posición intermedia dado que posee un $11,10 \%$ de sus viviendas desocupadas, y es cercano a los casos de Ituzaingó $(11,55 \%)$ y Esteban Echeverría (11,56\%).

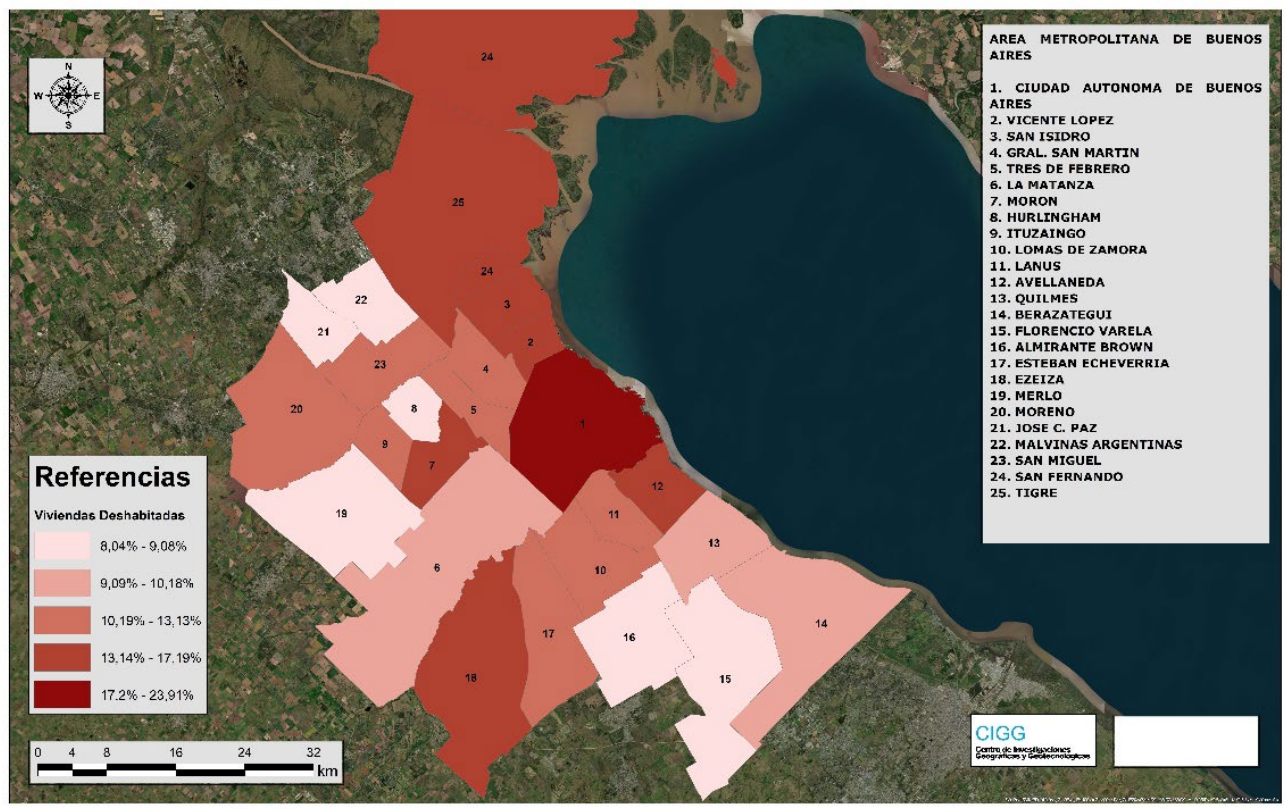

Figura 1. Porcentaje de viviendas deshabitadas en los partidos del Área Metropolitana de Buenos Aires (2010)

Fuente: Elaboración propia, en base a INDEC (2010)

De acuerdo al censo del 2010, cerca del $40 \%$ de la población de Ciudad Autónoma de Buenos Aires reside bajo el régimen de tenencia de la vivienda del alquiler o es ocupante de su vivienda, mientras que en los partidos del Área Metropolitana de Buenos Aires los ocupantes bajo la modalidad del alquiler son del 13,21\%. Estas personas no pueden acceder a la vivienda propia dado que existen restricciones vinculadas con la imposibilidad de ahorro (con una inflación que llega casi al $48 \%$ 
anual, como en el año 2018, y que -frente a la falta de intervención del Estado- se traslada al valor de los alquileres) y también con respecto al acceso al crédito hipotecario (por la inexistencia de créditos a tasas fijas, y que se ajusten al salario real del trabajador que se encuentra desfasado de la inflación) ${ }^{7}$.

Las viviendas desocupadas representan una problemática en Buenos Aires porque su incorporación en el mercado, junto con una regulación del mismo, favorecería el acceso a los alquileres ${ }^{8}$. Esto ocurre fundamentalmente porque la demanda insatisfecha corresponde a los sectores de nivel socioeconómico medios y medios bajos, cuando la mayor parte de los inmuebles ociosos se ubican, como ya dijimos, en las zonas más pudientes de la ciudad. Entonces la inyección de estos inmuebles al mercado no soluciona una demanda que parece extendida en los diferentes barrios, y que parece concentrarse en la zona sur de la ciudad. Si bien cabe aclarar, que esta inyección podría resultar una medida paliativa para contrarrestar las diferencias en el precio de los alquileres dentro del conjunto de la ciudad y, entonces, contribuir a la redistribución de la demanda.

\section{Algunas notas sobre el proceso de configuración de Las Lomitas}

Desde inicios de la década del 2000 se registran en la Región Metropolitana de Buenos Aires procesos de valorización de los centros tradicionales, que parecen replicar algunas características de las experiencias de renovación urbana de barrios de la Capital Federal como San Telmo (Herzer, H., 2008), Abasto (Carman, M., 2002; Baer, L., 2010), o como la invención de la zona conocida como Las Cañitas en el barrio de Palermo (lulita, A., 2018). La zona de estudio se ubica en la localidad cabecera del

\footnotetext{
7 “La inflación en 2018 fue del 47,6\%, la cifra más alta en los últimos 27 años" Diario La Nación. 15 de enero de 2019. Fuente: https://www.lanacion.com.ar/economia/dolar/inflacion-diciembre-2018-indecprecios-nid2211091

${ }^{8}$ La iniciativa de promover el alquiler de los inmuebles deshabitados podría inyectar unidades en el mercado, si bien su cantidad es insuficiente para mejorar el precio de los alquileres: se estima un total de 350.000 viviendas, al año 2015 , de las cuales no hay una estimación exacta de la cantidad que podrían ser habitadas. La incorporación de viviendas vacías es un proyecto del legislador Gustavo Vera, que imita a las medidas aplicadas en Holanda, Suecia y Dinamarca para paliar el déficit habitacional. Fuente: Diario La Nación. 17 de enero de 2015. https://www.lanacion.com.ar/buenos-aires/proponen-incorporar350000-viviendas-vacias-en-la-ciudad-al-mercado-inmobiliario-nid1760956
} 
partido de Lomas de Zamora, que también se llama Lomas de Zamora, y es donde se ubica la sede del gobierno municipal. El proceso de valorización del centro tradicional, que se estructura en torno de la estación ferroviaria Lomas de Zamora y sobre el eje de la calle peatonal Laprida, llevó a la revitalización y expansión de la zona comercial (Romano, B. e lulita, A., 2013; Romano, B., 2018ab). Este proceso fue acompañado por la expansión de edificios de departamentos, que se erigieron sobre el barrio residencial lindante con el centro tradicional. Una de las consecuencias fue el avance de las funciones de centro (como la expansión de locales comerciales, y de servicios como salud y bancarios) hacia el sur del centro tradicional, generando mutaciones no solamente en la dinámica social barrial sino también a nivel paisaje y de uso del suelo. En este sentido, muchas viviendas fueron reemplazadas por locales comerciales o mismo se demolieron para transformarse en edificios de departamentos.

La mayoría de los edificios de departamentos se construyeron en forma posterior al año 2000, y se concentraron en las 159 manzanas que se circunscriben a la zona que denominamos Área Central Expandida (ACE) ${ }^{9}$. Con fines metodológicos hemos dividido a Las Lomitas en Las Lomitas I y Las Lomitas II, con el objetivo de marcar no solamente su aparición cronológica sino también sus funciones; dado que en Lomitas I predominan los comercios y edificios de departamentos mientras que Lomitas II se caracteriza por concentrar fundamentalmente edificios de departamentos. También delimitamos una zona que llamamos Resto del Área Central Expandida que abarca la mencionada expansión de los edificios de departamentos y de algunos comercios, aunque de menor densidad en consonancia con el código de edificación vigente. Para la delimitación del Área Central Expandida se consideró el crecimiento de edificios de departamentos de más de 3 pisos de altura, la edad de las construcciones y la cantidad de pisos de los edificios. También se consideró la proliferación y distribución de los comercios. Posteriormente la misma ha sido ajustada a los radios censales correspondientes a los Censos Nacionales de Hogares, Población y Vivienda (INDEC) de los años 1991, 2001 y 2010, Figura 2.

\footnotetext{
${ }^{9}$ Si bien existió un primer proceso de verticalización en la década de 1990, que posibilitaba comprar departamentos en cuotas fijas en moneda fuerte (dólar estadounidense). Ese proceso se desaceleró como resultado de la crisis del 2001 y de la pérdida de la paridad cambiaria.
} 


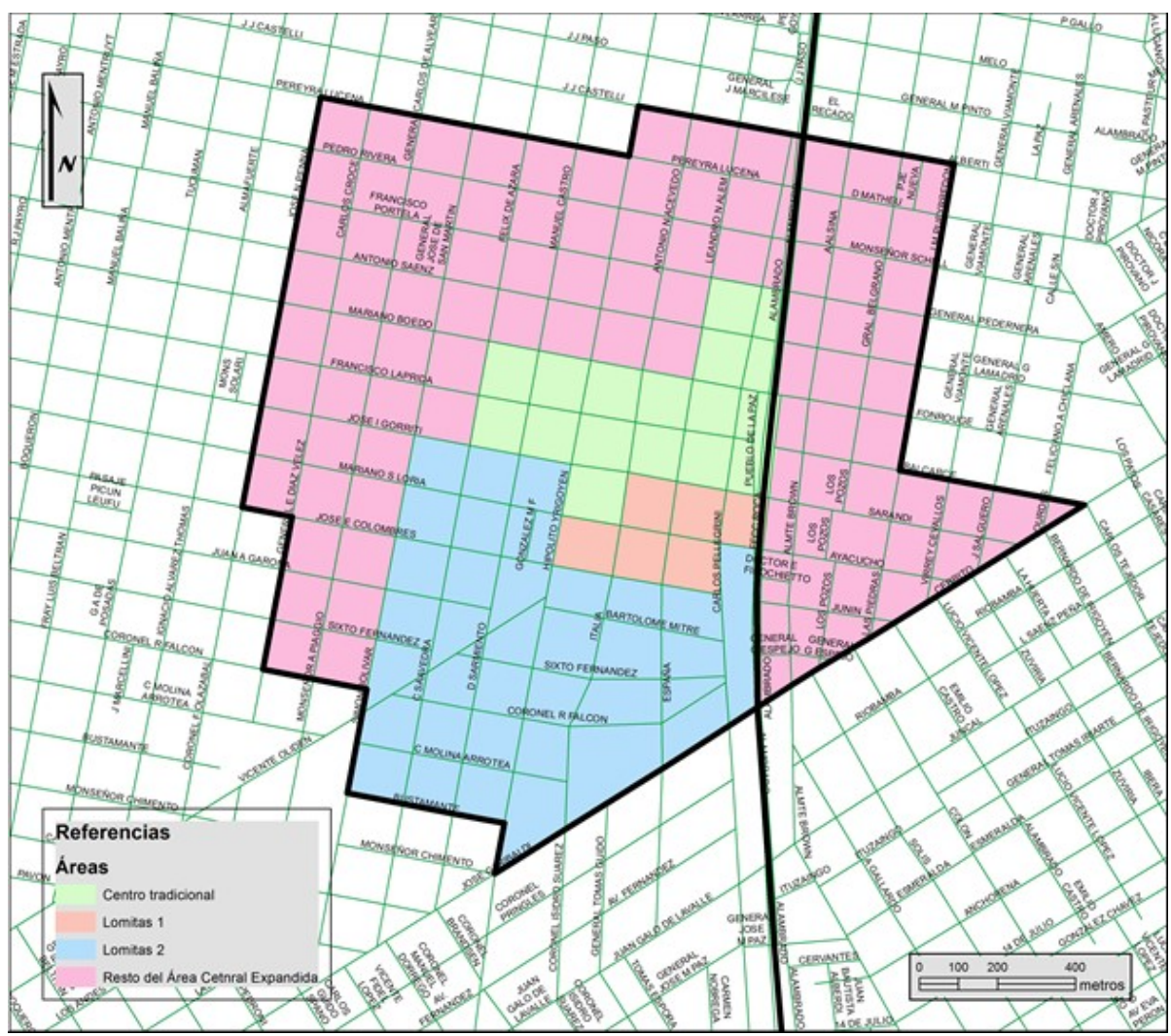

Figura 2. Área Central Expandida (ACE) en la localidad cabecera de Lomas de Zamora. Año 2014. Fuente: Elaboración propia, en base a información provista por Google Earth e INDEC (1991, 2001, 2010) A comienzos de la década del 2000 el desarrollo de la zona a través del aumento de la cantidad de edificios de departamentos y de la apertura de locales comerciales llevó a que los promotores inmobiliarios comenzaran a promocionar la zona llamándola "Las Lomitas". Esa denominación respondería a algunas características vinculadas con la creación de una imagen de ciudad, que la diferencia no solamente del resto de las ciudades del partido sino también dentro del propio centro lomense, y formaría parte indisociable del proceso de renovación urbana (Romano, B., 2018a). Esta zona se caracteriza por concentrar un proceso reciente de expansión comercial y de edificios de departamentos; y también por un proceso de valorización del patrimonio histórico-arquitectónico; que ha derivado -principalmente- en 
transformaciones del tradicional paisaje lomense y en el aumento del valor del suelo urbano. Numerosos medios de comunicación que acompañan y estimulan este proceso han rotulado al centro lomense como "el boom de Las Lomitas" (La Nación, 27 de febrero de 2018) ${ }^{10}$ o como "reducto chic de Lomas de Zamora" ${ }^{11}$, invocan de modo semántico la incorporación de nuevos territorios de distinción en el sur metropolitano; que parecen suceder, emular y acompañar a los existentes en la Ciudad Autónoma de Buenos Aires amparados bajo la lógica de la reurbanización especulativa inmobiliaria.

La mercantilización de la zona del centro lomense es dirigida a captar a un segmento de población de nivel socioeconómico medio y alto que históricamente residió en la zona, y que busca diferenciarse de los transeúntes y consumidores de la popular peatonal Laprida (Romano, B. e lulita, A., 2013; Romano, B., 2018ab). La construcción de una (renovada) imagen de ciudad responde por un lado a una estrategia para distinguir esa zona emergente de la del centro tradicional y, por otro lado, como una forma de emular a la zona de Las Cañitas, en el barrio de Palermo ${ }^{12}$.

En este proceso de construcción de la nueva zona comercial y residencial, participan no solamente los promotores inmobiliarios y comerciantes, sino también el gobierno local. El Estado crea condiciones para el desarrollo de la inversión inmobiliaria y, al mismo tiempo, lo incentiva invirtiendo en infraestructura y servicios urbanos que luego son aprovechados por los promotores inmobiliarios para maximizar su renta urbana. En este sentido se refuerza la seguridad pública, se mejora el alumbrado, la limpieza y los espacios públicos, muchas veces en detrimento de la preservación de la idiosincrasia lomense y al mismo tiempo apostando a un modelo de ciudad competitiva y moderna.

10 https://www.lanacion.com.ar/2112440-el-boom-de-las-lomitas-un-barrio-que-no-deja-de-crecer-enel-sur-del-conurbano

${ }^{11}$ http://www.revistaohlala.com/1460961-las-lomitas-conoce-el-reducto-chic-de-lomas-de-zamora

${ }^{12}$ Las Cañitas es la denominación informal y no oficial de un sector de unas 20 manzanas dentro del barrio de Palermo en la Ciudad Autónoma de Buenos Aires. Desde fines de los años '90 la zona ha venido experimentando una explosión de construcción de edificios de alta categoría y grandes torres, además de locales gastronómicos y de diseño; orientado al sector socioeconómico de ingresos medios-altos (lulita, A., 2018). 


\section{El fenómeno de las casas vacías en el Área Central Expandida}

El auge inmobiliario constructivo posterior a la llamada crisis del 2001, promovió la expansión de nuevas edificaciones. De acuerdo al relevamiento de edificios de departamentos realizado en el año 2015, en el Área Central Expandida, se contabilizaron un total de 408 edificios de departamentos. Como resultado, la cantidad de edificios de departamentos cuadriplicó a los existentes en la década de 1990, para esa misma zona (Romano, B., 2018b).

El análisis de los tres últimos censos demuestra que la cantidad de población en el Área Central Expandida tuvo una variación intercensal negativa entre 1991 y 2001 (2.488 habitantes), mientras que entre los años 2001 y 2010 podríamos decir que la población se mantuvo estable puesto que sufrió un leve aumento (+304 habitantes). Para el caso del partido de Lomas de Zamora la variación fue positiva en los tres periodos de análisis. Se evidencia en la tabla 1 que entre 1991 y 2001 el aumento de la cantidad de población en el partido de Lomas de Zamora fue del 3\%; mientras que entre 2001 y 2010 aumento a 4,2\%. Se registró, por lo tanto, entre los censos de 1991 y 2010, un aumento del 7,3\% en la cantidad de población para el conjunto del partido.

De la tabla 1, también se desprende que la mayor cantidad de habitantes se ubica en la zona que denominamos Resto del ACE. En esa zona se mantuvo un promedio de población que ronda los 11.000 habitantes por cada año censal, mientras que en Las Lomitas I la cantidad de personas no ha logrado superar los 1.600 habitantes en los mismos años censales. Por otra parte, cabe destacar que se produjo una disminución intercensal generalizada de la cantidad de población en todas las zonas que componen el Área Central Expandida en el período de análisis, con excepción de la zona del Centro tradicional en donde la población aumentó. Además, la cantidad de población de Las Lomitas, en conjunto, no logra superar a la del Resto del ACE en ningún año censal mientras que duplica a la contenida en el Centro tradicional. 


\begin{tabular}{|l|r|r|r|}
\hline \multirow{2}{*}{\multicolumn{2}{|c|}{ Zonas }} & \multicolumn{3}{c|}{ Cantidad de población (habitantes) } \\
\cline { 2 - 4 } & \multicolumn{1}{c|}{$\mathbf{1 9 9 1}$} & \multicolumn{1}{c|}{$\mathbf{2 0 0 1}$} & \multicolumn{1}{c|}{$\mathbf{2 0 1 0}$} \\
\hline Las Lomitas I & 1.598 & 1.364 & 1.311 \\
\hline Las Lomitas II & 5.217 & 4.832 & 4.870 \\
\hline Centro tradicional & 2.106 & 1.827 & 2.499 \\
\hline Resto del Área Central Expandida & 12.536 & 10.946 & 10.593 \\
\hline Total Área Central Expandida & 21.457 & 18.969 & 19.273 \\
\hline Total partido Lomas de Zamora & 574.330 & 591.345 & 616.279 \\
\hline
\end{tabular}

Tabla 1. Cantidad de población en Área Central Expandida (ACE), en números absolutos. Fuente: Elaboración propia, en base a INDEC 1991, 2001, 2010.

A lo largo de los tres censos de población, se deprende la misma tendencia para el Área Central Expandida: la zona del Resto del Área Central Expandida contiene más del 55\% de la población del Área Central Expandida, seguido por Las Lomitas II (que se mantiene en el orden del $25 \%$, estable, para el mismo periodo) y luego por el Centro tradicional que pasó de concentrar el 9,8\% de la población del Área Central Expandida en el censo del año 1991 al 13\% en el último censo del 2010. La zona que agrupa el menor porcentaje de población del Área Central Expandida es Las Lomitas I, que pasó de concentrar el 7,4\% en el censo de 1991 a 6,8\% en 2010. En este punto conviene resaltar, a modo de síntesis, que la cantidad de población del Área Central Expandida, tanto en números absolutos como en porcentajes, es estable y que su distribución tampoco sufrió variaciones con el surgimiento de Las Lomitas, en el periodo poscrisis 2001. Entonces ¿Quiénes ocupan las nuevas viviendas que surgieron a raíz de la expansión de edificios de departamentos? El análisis de los tres últimos censos de hogares población y vivienda, demuestra una disminución sostenida del porcentaje de viviendas ocupadas, tabla 2 . 


\begin{tabular}{|l|r|r|r|r|r|r|}
\hline \multirow{2}{*}{ Zonas } & \multicolumn{2}{|c|}{1991} & \multicolumn{2}{c|}{$\mathbf{2 0 0 1}$} & \multicolumn{2}{c|}{$\mathbf{2 0 1 0}$} \\
\cline { 2 - 7 } & \multicolumn{1}{|c|}{ Ocup. } & Desocup. & Ocup. & \multicolumn{1}{c|}{ Desocup. } & Ocup. & Desocup. \\
\hline Las Lomitas I & $79,90 \%$ & $20,10 \%$ & $64,10 \%$ & $35,90 \%$ & $60,80 \%$ & $39,20 \%$ \\
\hline Las Lomitas II & $86,20 \%$ & $13,80 \%$ & $75,30 \%$ & $24,70 \%$ & $67,30 \%$ & $32,70 \%$ \\
\hline Centro tradicional & $77,10 \%$ & $22,90 \%$ & $60,70 \%$ & $39,30 \%$ & $56,20 \%$ & $43,80 \%$ \\
\hline Resto Area Central Expandida & $83,30 \%$ & $16,70 \%$ & $76,00 \%$ & $24,00 \%$ & $74,90 \%$ & $25,10 \%$ \\
\hline Total Area Central Expandida & $82,80 \%$ & $17,20 \%$ & $72,40 \%$ & $27,60 \%$ & $68,30 \%$ & $31,70 \%$ \\
\hline Total partido Lomas de Zamora & $92,40 \%$ & $7,60 \%$ & $87,00 \%$ & $13,00 \%$ & $88,90 \%$ & $11,10 \%$ \\
\hline
\end{tabular}

Tabla 2. Cantidad de viviendas ocupadas y desocupadas en Área Central Expandida (ACE) y partido de Lomas de Zamora, en porcentaje.

Fuente: Elaboración propia, en base a INDEC 1991, 2001, 2010.

Entre 1991 y 2010 disminuyo alrededor del 20\% el porcentaje de viviendas ocupadas: se pasó del 82\% ocupado en el Área Central Expandida en el año 1991 al 68,3\% en el censo del 2010. Como contrapartida, aumentó la cantidad de viviendas desocupadas: pasando de 17,2\% en el censo de 1991 a 31,7\% en 2010. Esta tendencia se visualiza para todas las zonas de estudio, si bien cabe destacar un aumento (poco significativo) del 1,9 \% para el Total partido Lomas de Zamora. Los mayores porcentajes de disminución de viviendas ocupadas se registran entre los censos de 1991 y 2001, en donde la variación intercensal es de un promedio del $11.3 \%$.

La zona que presentó el mayor porcentaje de viviendas ocupadas fue el total partido de Lomas de Zamora, seguido por Las Lomitas II y luego por Resto del Área Central Expandida. Por otra parte, las zonas que presentan los mayores porcentajes de viviendas desocupadas son Las Lomitas I y Centro tradicional. Cabe destacar que, según el último censo, el porcentaje de viviendas desocupadas en la zona del Centro tradicional era del $43.8 \%$. Este valor podríamos calificarlo como preocupante, puesto que más del $40 \%$ de las viviendas están desocupadas y se ubican en el centro neurálgico del partido, dejando ocioso el consumo de servicios urbanos e imposibilitando un desarrollo territorial local sostenible.

En números absolutos, podemos decir que la cantidad total de viviendas se duplicó, mientras que la cantidad de viviendas desocupadas prácticamente se triplicó. En este sentido, en el censo de 1991 existían 1492 viviendas desocupadas en el Área Central 
Expandida y en 2010 se contaban 3774 viviendas. Al mismo tiempo, cabe destacar que dentro de las zonas que componen el ACE, la variación intercensal demuestra que se multiplicaron las viviendas vacías. En el caso de las viviendas ocupadas, se aprecia para el intervalo 1991 - 2001 una disminución absoluta, mientras que en el intervalo 2001 - 2010 se revierte esta tendencia.

Si nos proponemos, nuevamente, relacionar la cantidad de viviendas con la población existente en el ACE podemos decir que existen 0,6 viviendas por habitante en el año 1991; mientras que en el año 2010 disminuyó la cantidad de población y aumentó la cantidad de viviendas. Es decir, que en el año 2010 existían 0,4 viviendas por habitante lo que representa, entonces, más viviendas para menos propietarios.

Entonces, ¿Por qué proliferaron las viviendas vacías? ¿Qué tipo de medidas podrían detener la proliferación de viviendas vacías?

El suelo urbano es un bien escaso, único e irrepetible. La propiedad privada permite que el propietario monopolice ciertas características únicas del suelo urbano, determinadas fundamentalmente por los atributos de su localización y por la incorporación de un valor producido en forma colectiva: la urbanización (Topalov, C., 1978). Es decir que el propietario se apropia de una parte de la valorización generada en el proceso de urbanización, sin realizar ningún esfuerzo y en detrimento del consumidor final; que ve incorporado dicho valor al costo de la mercancía final.

La retención de la vivienda, es decir no colocarla en el mercado inmobiliario, contribuye a restringir el derecho a la ciudad, en los términos planteados por Lefebvre (1978), y que la vivienda sea un bien de cambio y que no cumpla su función social. La decisión de los propietarios de subutilizar la vivienda le imprime un costo económico a toda la sociedad, que se llama externalidad, porque no es posible aprovechar las ventajas de la aglomeración y de red que son inherentes a esa vivienda (Polinelli, J. et al. 2013). Las externalidades se definen como aquellas decisiones de consumo que toman los individuos, empresas u hogares y que afectan a terceros que no participan directamente en esas transacciones. La afectación se refiere a, por ejemplo, el aumento generalizado del precio de los inmuebles y de sus alquileres y a la falta de oferta dirigida a los sectores sociales medios y populares. 
Frente a los obstáculos a los procesos de urbanización que generan los inmuebles ociosos, agrupaciones como la Asociación Inquilinos Agrupados aseguran que la intervención del Estado regularía el uso del suelo urbano y garantizaría el derecho a la vivienda, tal como lo establece la constitución nacional ${ }^{13}$. En este sentido, y de acuerdo a autores como Zernobi, F., (2012), Fernández Wagner, R., (2014); Rolnik, R., (2017); la gravación impositiva de las viviendas ociosas podría estimular la incorporación de inmuebles al mercado inmobiliario y evitaría socializar costos de decisiones privadas (como la de retener inmuebles).

El impuesto propuesto, que surge como una iniciativa a partir de la discusión sobre la ley de Alquileres en el año 2017, no gravaría la propiedad inmobiliaria sino la especulación; y lo pagaría el propietario ${ }^{14}$. El impuesto se aplicaría sobre viviendas vacías, en condiciones de habitabilidad y que no están destinadas al alquiler temporario de turistas. La vivienda ociosa se detectaría a través del nivel de consumo de los servicios, como electricidad, gas y agua. Cuando se demuestra que la propiedad no está en uso, se le aplica un impuesto que iría aumentando mes a mes. Uno de los efectos del impuesto sería disminuir el beneficio del propietario por la retención del inmueble, y bajar la expectativa por la especulación inmobiliaria. El objetivo principal no es que el Estado recaude sino penalizar la tenencia de bienes inmuebles ociosos; y que, llegado el caso, se convierta en un instrumento de recaudación al servicio de la planificación urbana ${ }^{15}$.

Durante el año 2020, finalmente, se aprobó la Nueva Ley de Alquileres. La misma rige desde el 10 de Julio bajo el número $27551 / 20^{16} \mathrm{y}$, básicamente, establece la extensión de los contratos a tres años, la limitación del depósito inicial al equivalente a un mes de alquiler, la actualización anual del precio del alquiler a partir de una fórmula que combina la evolución de los precios con la de los salarios formales, una

\footnotetext{
13 https://www.infobae.com/economia/2018/06/19/alquileres-proponen-crear-un-impuesto-para-losdepartamentos-vacios/

${ }^{14}$ https://www.eldia.com/nota/2016-3-16-impulsan-un-impuesto-extra-a-las-viviendas-deshabitadas

15 "Según Inquilinos Agrupados, la fijación de un impuesto podría crear un fondo para la construcción de viviendas públicas que se puedan alquilar". Fuente: https://www.infobae.com/economia/2018/06/19/ alquileres-proponen-crear-un-impuesto-para-los-departamentos-vacios/

16 https://www.argentina.gob.ar/noticias/rige-la-nueva-ley-de-alquileres
} 
ampliación de las garantías que aporta el inquilino, que las expensas extraordinarias corran por parte del propietario y la obligación de declarar el alquiler en la AFIP. La norma fue apoyada por las organizaciones de inquilinos fundamentalmente por la extensión de los plazos del contrato y porque evita algunos abusos de inmobiliarias sobre el depósito inicial y también de propietarios respecto a aumentos y expensas. En contraparte, algunas grandes inmobiliarias se declararon en contra de la nueva ley de alquileres porque entienden que disminuirá la oferta de propiedades en alquiler e incrementará su precio ${ }^{17}$.

Con respecto a las viviendas ociosas, la idea de cobrar un impuesto sigue siendo un proyecto $^{18}$ y aún no está contemplado dentro de la Nueva Ley de Alquileres cuya sanción, cabe destacar, se apuró como consecuencia de los efectos de la pandemia del COVID19 sobre los salarios de los trabajadores ${ }^{19}$. La situación actual exige acompañar la Nueva Ley de Alquileres con una regulación con impuestos progresivos a las viviendas vacías y baldíos, estimulando a los propietarios a ofrecer sus viviendas en alquiler, de modo de reducir el precio de los alquileres al incrementar la oferta y reducir la demanda de viviendas en alquiler. Además, incentivaría el blanqueo de los alquileres ante la AFIP para declarar la ocupación de la vivienda y evitar, entonces, impuestos a la aplicación de impuestos progresivos.

\section{CONCLUSIONES}

La crisis habitacional en Argentina, que se arrastra desde hace décadas, se agravó en los últimos años no solamente por el aumento de la inflación, en donde el alquiler de la vivienda logra consumir alrededor del $40 \%$ de los ingresos de un hogar, sino por la falta de regulación de los precios del suelo. La iniciativa del proyecto del gravado de los inmuebles ociosos apunta a aumentar su oferta en el mercado, equilibrar los valores de los precios y diluir la demanda entre los distintos barrios de

\footnotetext{
17 https://www.pagina12.com.ar/271760-el-complejo-mercado-de-alquiler-de-viviendas

18 https://www.tiempoar.com.ar/nota/impulsan-un-proyecto-para-cobrar-impuestos-a-las-viviendasociosas-de-la-ciudad

${ }^{19}$ https://www.argentina.gob.ar/habitat/alquileres-medidas-de-/emergencia-por-covid-19
} 
la Ciudad Autónoma y de los partidos que componen el Área Metropolitana de Buenos Aires.

El porcentaje de viviendas vacías creció no solamente en los barrios de la Ciudad Autónoma de Buenos Aires, sino también en la ciudad de Lomas de Zamora. Al respecto, el porcentaje de viviendas vacías en el Área Central Expandida del centro de Lomas de Zamora pasó de $17.2 \%$ a 31.7\%, entre los años censales 1991 y 2010; lo que indica que la cantidad de viviendas vacías se duplico. Esta tendencia es también detectable en los barrios de la CABA, en donde según el último censo de hogares, población y viviendas (INDEC, 2010) Palermo y Recoleta parecen ostentar los mayores porcentajes de viviendas ociosas: $29,47 \%$ y $34,50 \%$, respectivamente, lo que representa algunas simetrías con nuestra zona de estudio. Desde aquí se desprenden nuevas preguntas de investigación, que apuntan a comprender ¿Qué relaciones podrían establecerse entre los barrios que históricamente aglutinaron las mejores condiciones sociohabitacionales y aquellos que concentran la mayor cantidad de viviendas ociosas? y ¿̇en qué medida la disposición espacial de viviendas ociosas determina configuraciones territoriales excluyentes?, es decir ¿cómo la falta de regulación estatal al inmueble ocioso empuja a la pobreza a aquellos hogares que no logran cubrir el (ascendente) precio de los alquileres? Y entonces ¿Cómo la proliferación de viviendas ociosas restringe el derecho a vivir y habitar la ciudad?

Los especialistas aseguran que, para realizar una intervención estatal en el mercado de alquileres argentino a través de la incorporación de viviendas vacías, tal como lo hicieron países como Francia, Gran Bretaña, Alemania (Fernández Wagner, R., 2014; Rolnik, R., 2017), es preciso, en primer lugar, lograr que los propietarios den factura por los alquileres y que exista un registro de todos los contratos de alquiler (Rodríguez, M. C., et al 2016). También es preciso mejorar las mediciones que realiza el INDEC, puesto que el censo proporciona una imagen fija, mientras que la utilización que se hace de las viviendas es una circunstancia sujeta a cambios no siempre previsibles en sus motivaciones ni en su frecuencia. La idea de vivienda desocupada o vacía hace referencia a una situación temporal y por tanto cambiante que conduce al concepto de flujos o número de viviendas que pasan a estar vacías o que dejan de estarlo a lo largo de un determinado periodo de tiempo. Además del análisis del stock de viviendas que están desocupadas en un momento dado, el 


\section{estudio de las causas de desocupación y las características de esas viviendas son un paso necesario para diagnosticar sobre el fenómeno.}

\section{BIBLIOGRAFÍA}

Álvarez, G. e lulita, A. (2013). Cambios en la división social del espacio metropolitano en el Área Metropolitana de Buenos Aires. República Argentina. Período 1980-2010. Actas del 14 Encuentro de Geógrafos de América Latina (EGAL), Lima, Perú, 8 y el 12 de abril de 2013.

Baer, L. (2010). Transformaciones urbanas y de la estructura social de un barrio de la ciudad de Buenos Aires. Economía, sociedad y territorio, X, (33), 283-325.

Baer, L. (2012). Mercados de suelo y producción de vivienda en Buenos Aires y su área metropolitana. Tendencias recientes de desarrollo urbano y acceso a la ciudad. Iberoamericana de Urbanismo, (8), España, 43-58.

Carman, M. (2002). Una mirada antropológica sobre un evento político: la inauguración del Shopping Abasto de Buenos Aires. III Jornadas de patrimonio intangible. El espacio cultural de los mitos, ritos, leyendas, celebraciones y devociones. Centro Cultural San Martín, 26 y 27 de agosto de 2002. Buenos Aires.

Comisión de Vivienda del Consejo Económico y Social (2016). Diagnóstico socio-habitacional de la Ciudad Autónoma de Buenos Aires. Rodríguez, M.C. (coord.) 1a ed. Buenos Aires.

Dalle, P. (2010). Estratificación social y movilidad en Argentina (1870-2010). Huellas de su conformación socio-histórica y significados de los cambios recientes. Revista de Trabajo. Año 6, (8), 59-82.

Del Río, J. P. (2014). Transformaciones habitacionales en la Región Metropolitana de Buenos Aires: El pasaje del neoliberalismo al neodesarrollismo urbano. Geograficando, 10, (2). Buenos Aires: Universidad Nacional de La Plata.

Dirección General de Estadística Y Censos (Ministerio de Hacienda GCBA) (2014). La condición de ocupación de las viviendas particulares en la Ciudad de Buenos Aires. Informe de resultados 696. Junio de 2014.

Guevara, T. (2014). Transformaciones territoriales en la Región Metropolitana de Buenos Aires y reconfiguración del régimen de acumulación en la década neo-desarrollista. Quid, (4), Buenos Aires: FCSUBA, 115-136.

Harvey, D. (2001). De la gestión al empresarialismo: la transformación de la gobernanza urbana en el capitalismo tardío, Espacios de Capital, hacia una geografía crítica, Madrid: Akal (2007).

Herzer, H. (coord.) (2008). Con el corazón mirando al sur, Buenos Aires: Ed. Espacio.

Instituto Nacional de Estadística y Censo (INDEC) Censos Nacionales de Hogares, Población y Vivienda. 1991, 2001 y 2010. 
Iulita, A. (2018). Transformaciones sociales y urbanas en la Ciudad Autónoma de Buenos Aires. La dinámica del capital inmobiliario en "Las Cañitas" (1991-2016), IX Congreso Internacional de Geografía de América Latina. Toledo. 12 al 14 de septiembre de 2018. Cuenca: Ediciones de la Universidad de Castilla-La Mancha.

Lefebvre, H. (1978). El derecho a la ciudad. Barcelona: Ed. Península.

Polinelli, J, Guevara, T. y Dondo, M. (2013). El Problema de los Inmuebles Urbanos Ociosos. Fundamentos de una propuesta de regulación para los municipios argentinos. Teuken Bidikay, (04), 87-106.

Rodríguez, M. C, Boldrinl, P. y Fernández Wagner, R. (2016). Habitar en contextos de desigualdad. 1a ed., Ciudad Autónoma de Buenos Aires: Proyecto Habitar.

Rolnik, R. (2017). La guerra de Los Lugares. La colonización de La tierra y La vivienda en La era de Las finanzas, Santiago de Chile: Lom.

Romano, B. (2018a). Revitalización del espacio público en el centro de Lomas de Zamora, a través de los Centros Comerciales a Cielo Abierto. Buenos Aires. Argentina. En Vidal-Koppmann, S. (comp.) Dinámica socio-espacial de regiones metropolitanas. Claves para el análisis de un fenómeno complejo,171-196, IMHICIHU. CONICET.

Romano, B. (2018b). La inquilinización en el proceso de renovación urbana del centro de la ciudad de Lomas de Zamora, Buenos Aires. IX Congreso Internacional de Geografía de América Latin, Toledo, 12 al 14 de septiembre de 2018, Cuenca: Ediciones de la Universidad de Castilla-La Mancha. 435-453.

Romano, B. e lulita, A. (2013). Transformaciones urbanas en el partido de Lomas de Zamora ¿Hacia la emergencia de nuevas centralidades o hacia el aburguesamiento de los centros tradicionales? El caso de Las Lomitas en el Aglomerado Gran Buenos Aires, Anales del XIV Encuentro de Geógrafos de América Latina. 8 al 11 de abril de 2013, Lima, Perú.

Topalov, C. (1978). La urbanización capitalista. Algunos elementos para su análisis. México: Edicol.

Torres, H. (1978). El Mapa Social de Buenos Aires en 1943, 1947 y 1960. Buenos Aires y los Modelos urbanos, Desarrollo Económico, XVIII (70), México, 163-204.

Torres, H. (2001). Cambios socioterritoriales en Buenos Aires durante la década de 1990, EURE, .27, (80), Santiago mayo 2001. 33-56.

Zerboni, F. (2012). No hay política de vivienda sin recursos, Contrapunto, (1), Uruguay, 53-61.

\section{Otras fuentes consultadas:}

Asiain, A. (2020). El complejo mercado de alquiler de viviendas, Diario Página/12. https://www.pagina12.com.ar/271760-el-complejo-mercado-de-alquiler-de-viviendas Consultado en octubre/2020 
Defensoría del pueblo (2015). La situación habitacional en la Ciudad Autónoma de Buenos Aires. Ciudad Autónoma de Buenos Aires. http://www.defensoria.org.ar/wp-content/uploads/2015/09/Situacion Habitiacional-1.pdf Consultado en octubre/2020

Diamante, S. (2019). La inflación en 2018 fue del 47,6\%, la cifra más alta en los últimos 27 años, Diario La Nación. https://www.lanacion.com.ar/economia/dolar/inflacion-diciembre-2018-indec-precios-nid2211 091 Consultado en octubre /2020

Diario El Día (2016). Impulsan un impuesto extra a las viviendas deshabitadas. https://www.eldia.com/nota/2016-3-16-impulsan-un-impuesto-extra-a-las-viviendas-deshabitadas Consultado en octubre /2020.

Diario Infobae (2018). Alquileres: proponen crear un impuesto para los departamentos vacíos. https://www.infobae.com/economia/2018/06/19/alquileres-proponen-crear-un-impuesto-para-losdepartamentos-vacios/ Consultado en octubre/ 2020

Diario La Nación (2015). Proponen incorporar 350.000 viviendas vacías en la ciudad al mercado inmobiliario. https://www.lanacion.com.ar/buenos-aires/proponen-incorporar-350000-viviendas-vaciasen-la-ciudad-al-mercado-inmobiliario-nid1760956 Consultado en octubre/ 2020

Diario La Nación (2018). El boom de Las Lomitas: un barrio que no deja de crecer en el sur del conurbano. https://www.lanacion.com.ar/sociedad/el-boom-de-las-lomitas-un-barrio-que-no-deja-de-crecer-en-elsur-del-conurbano-nid2112440 Consultado en octubre/ 2020

Diario Tiempo Argentino (2020). Impulsan un proyecto para cobrar impuesto a las viviendas vacías de la Ciudad. https://www.tiempoar.com.ar/nota/impulsan-un-proyecto-para-cobrar-impuestos-a-las-viviend as-ociosas-de-la-ciudad Consultado en octubre/2020

Fernández Wagner, R. (2014). Déficit habitacional, Diario Página/12 https://www.pagina12.com. ar/diario/suplementos/cash/17-7449-2014-02-16.html Consultado en octubre/ 2020

Centro de Estudios Legales y Sociales (CELS), (2019). Viviendas vacías en la ciudad y emergencia habitacional. https://www.cels.org.ar/web/2019/08/viviendas-vacias-en-la-ciudad-y-emergencia-habita cional/ Consultado en octubre/ 2020

Ministerio de Desarrollo Territorial y Hábitat (2020). Alquileres: medidas de emergencia por COVID-19. https://www.argentina.gob.ar/habitat/alquileres-medidas-de-/emergencia-por-covid-19 Consultado en octubre/2020

Ministerio de Desarrollo Territorial y Hábitat (2020). Rige la nueva ley de alquileres. https://www.argentina.gob.ar/noticias/rige-la-nueva-ley-de-alquileres Consultado en octubre/2020 


\section{LA AUTORA}

Bárbara Teresa Romano es Profesora, Licenciada y Doctora en Geografía por la Universidad de Buenos Aires (UBA). También es Especialista en Planificación Urbana y Regional por la Facultad de Arquitectura, Diseño y Urbanismo de la UBA. En la actualidad es becaria posdoctoral del CONICET y se desempeña como docente e investigadora en la Universidad Nacional de Tres de Febrero. Directora de proyecto en el Centro de Investigaciones Geográficas y Geotecnológicas (CIGG-UNTREF), y participa como investigadora en el Centro de Estudios del Transporte Área Metropolitana (CETAM-FADU-UBA), y en el Instituto Multidisciplinario de Historia y Ciencias Humanas (IMHICIHU-CONICET), en temáticas referidas a procesos de renovación urbana, generación de nuevas centralidades y Gestión urbana local en la Región Metropolitana de Buenos Aires.

Jromano@untref.edu.ar 